\title{
The travelling sonnet: The key role of technology in an inter-university cultural heritage project
}

Noemy Berbel-Gómez, University of the Balearic Islands, Spain

Alberto Cabedo-Mas, University Jaume I of Castellon, Spain

María-Elena Riaño-Galán, University of Cantabria, Spain

Cristina Arriaga-Sanz and Maravillas Díaz-Gómez, University of the Basque Country, Spain

\begin{abstract}
Students on the undergraduate degree in Primary Education in Spain took part in this inter-university experience within the subject of Didactics of Musical Expression. Eleven teachers and 307 students from four Spanish universities were involved in the experience, which took place in the academic year 2012-2013. The four universities were the University of the Basque Country, the University of Cantabria, University Jaume I of Castellon and the University of the Balearic Islands. The aim of the experience was to discover the traditional culture in various Spanish regions through an interdisciplinary and creative project. Based on cooperative methodology, each class in the four universities was divided into work groups of five to seven students. Technologies played an essential role in developing and coordinating the experience, as the students were able to interact and learn about the work being carried out in the other universities through virtual platforms and networks. The results of the evaluation process undertaken with the students and teachers showed that the experience had helped them to acquire basic competencies and knowledge about intangible cultural
\end{abstract}


heritage and that it was a source of exchange and enrichment for both students and teachers.

\section{Keywords}

didactics of musical expression

technology

inter-university experience

basic competencies

intangible cultural heritage

teacher education

\section{Introduction}

The Bachelor's Degrees in Infant and Primary Education offered by Spanish universities, both of which are four-year undergraduate degrees, include the speciality of music education. Future primary school teachers (qualified to teach children between the ages of 6 and 12) take the specific subject of Didactics of Musical Expression in their second year, which is worth six credits and is part of the Musical, Plastic and Visual Arts Education module. This module is designed to provide students with the following competencies:

Understanding of the principles that the arts contribute to cultural, personal and social education. Knowledge about the artistic, audio-visual and musical aspects of the school art education curriculum. Knowledge of the resources to encourage lifelong participation in musical and artistic activities both inside and outside 
school. Ability to develop and evaluate curriculum content through appropriate teaching resources and foster the corresponding competencies in students.

(Ministry of Education of Spain 2007: 53750)

In addition to extending the competencies acquired during their initial training, future teachers will therefore develop other academic and personal skills.

To this end, an educational project was carried out in four universities from different regions of Spain with the aim of investigating the didactic aspects of heritage that, through education and the acquisition of basic competencies, increase knowledge of our culture. It was designed to actively and meaningfully enhance students' appreciation of the importance of their region's cultural roots and enable them to evaluate signs of a common musical, cultural and traditional identity. Before students are presented with musical challenges that involve learning unknown structures and sound languages, they should be encouraged to experience the feelings that come from working with more familiar material (Froehlich 2007).

The UNESCO (2003) Convention for the Safeguarding of Intangible Cultural Heritage, adopted by the 32nd session of the General Conference in October 2003 and which came into force on 20 April, was also taken into account in the project design. Four of its objectives are:

1. To safeguard the intangible cultural heritage;

2. To ensure respect for the intangible cultural heritage of the communities, groups and individuals concerned;

3. To raise awareness at the local, national and international levels of the intangible cultural heritage; and 
4. To ensure reciprocal recognition of the intangible cultural heritage among countries and international cooperation and assistance.

The experience also aimed to provide a platform for a common and inclusive arts (music, plastic and visual arts) education activity. To this end, the proposals and suggestions formulated in the context of the European Higher Education Area (EHEA) were taken into account. In this context, the European Parliament 'encourages the prioritisation of ICT education during initial and subsequent training', with the aim of incorporating technology as a pillar of experience to integrate different disciplines and sound and visual resources, thereby fostering new approaches in artistic education (Giráldez Hayes 2013). The EHEA has brought new challenges, particularly in learning, and the need to meet the demands of twenty-first-century school has led to an increase in the knowledge and competencies demanded.

\section{Theoretical framework and context of the experience}

According to the UNESCO guidelines for higher education, students are the main actors in their learning process, and institutions should provide access to 'new pedagogical and didactical approaches to facilitate the acquisition of skills, competencies and abilities for communication, creative and critical analysis, independent thinking and team work in multicultural contexts, where creativity also involves combining traditional or local knowledge and know-how with advanced science and technology’ (1998). This classroom experience, entitled 'The travelling sonnet', came from the idea of travel as a metaphor of collective identity, comprising a geographical and cultural diversity (Malbrán 2010), and from a need to share and integrate, through music education, 
different areas of knowledge using a competency-based approach to respond to the principle of meaningful learning. The development of basic competencies allows, requires and strengthens dialogue among subject areas that can at times be excessively fragmented, and aims to enable students to discover new and different relationships between the contents they study, thereby encouraging mechanisms for autonomous thinking and learning (Roegiers 2007; Escamilla 2008, 2009). To this end, the study was based on cooperative methodology and, following Johnson, Johnson and Holubec (1994), it emphasized the importance of teamwork and individual and group responsibility both during the process and in carrying out and resolving the final tasks.

\section{Aims}

Our interest therefore lay in ensuring that students took on a number of roles in individual or group activities in either face-to-face or virtual contexts. Specific aims were therefore set out for each role.

In the role of researcher, the students compiled relevant information by searching and selecting documentary and ethnographic sources, exploring fundamental contents, discovering significant authors and carrying out analytical and summarizing tasks. The aims of this role were as follows:

- To explore the didactic aspects of heritage that contribute to knowledge about heritage through education and the acquisition of key competencies;

- To actively and meaningfully value the importance of the origins of their autonomous region; and

- To analyse shared identity markers in manifestations of music, culture and tradition. 
In their role as creators, the students gained personal experience of writing, composing, recording and editing through their participation in the integrated arts project in which the expressive languages and the specific techniques for each language were learnt through practice. The aims of this role were as follows:

- To experience and create audio-visual proposals that prepare them for selflearning using ICTs; and

- To acquire an attitude of participation and reflection in integrating different artistic languages from a creative and didactic perspective.

Finally, the role of evaluators enabled the students to develop a critical sense of themselves and others through the strategies described later in the article.

\section{Participant sample}

The proposal was designed with the participation of eleven teachers from the subject areas of music, literature, technology and visual arts at the following universities: University of the Basque Country (UPV), University of Cantabria (UC), University Jaume I of Castellón (UJI) and University of the Balearic Islands (UIB). A total of 307 teacher-training students from these universities participated in the project, which took place during the first semester of the 2013-2014 academic year.

The students in each university were asked to form groups of between five and seven members, following a cooperative approach; the students were left to organize their own groups without any set criteria. 


\section{Cooperative methodology: The phases of the experience}

\section{Documentary phase and analysis}

Each group was randomly allocated a core topic or thread that they used as a base to write a sonnet and set it to music. The core topics or threads, agreed upon by the teachers from the four universities, were flora and fauna, landscape, climate, existential reflection, death, love, cuisine, music and dance, and peoples and traditions; each topic would be approached from the perspective of each of the four regions.

This initial stage aimed to allow the students to acquire a broader understanding of the cultural heritage of their own environment. The literature component entailed searching for outstanding authors of sonnets at a regional, national or international level. Students studied an anthology of the most renowned sonnets in history, which gave them notions of metrics, and an appreciation of the attraction of this poetic form.

The language of music component began with an extensive search after which students selected traditional songs from each geographical region represented. Each work group in the four universities drew up a list of songs related to their particular topic. Throughout this process they prepared a portfolio or dossier compiling all the information on each song, the lyrics, the score, recordings, various adaptations, etc. The students also researched the geographical area associated with each song, exploring the lyrical aspects related to the topic, the origins, and the historical evolution of each piece. This process was completed with images, notes and other information of interest that resulted in some very useful educational material that students could use in their future teaching careers.

They also analysed the elements of musical language necessary to thoroughly understand each song; these elements would help them in the subsequent music creation phase. The main elements studied were rhythm (beat, metrics, bars, phrasing, rhythmic 
formulae), melody (syllabic singing, tessitura, ambit, intervals, scales, melodic direction, tonality, modality, the text-music relationship) and harmony (harmonic intervals, chords, accompaniments, textures).

\section{Creative phase}

The students expressed some uncertainty about embarking on the creative process: first, writing a sonnet; second, setting it to music; and finally, producing the audio-visual piece. All these tasks require positive, flexible and collaborative attitudes, as well as the ability to take the risks entailed in all creative and innovative work.

\section{The sonnet}

The literature teachers from each university proposed that each group write a sonnet related to their topic. Three languages were represented in the regions of the participating universities: Castilian in Cantabria, Basque in the Basque Country and Catalan in Castellón (Valencian Community) and the Balearic Islands. The linguistic richness of each region was therefore clearly reflected as a part of its cultural heritage.

\section{The music}

Once the sonnets had been written they were set to music using both vocal and instrumental expression. To help the students compose the music, the teachers from the area of music suggested the following task sequence:

- The musical structure begins with an introduction in which the students sing the traditional melody of the selected song with instrumental accompaniment; a member of the group might recite the sonnet. 
- The four line stanzas in the sonnet, known as quartets, are recited (spoken voice) and accompanied by instrumental background music that repeats the same traditional melody from the introduction enriched with effects such as voices, whispers, noises, sounds taken from digital sources, etc., all of which interplay to create a blend of textures and soundscapes.

- During the three line stanzas, or tercets, the students compose a vocal and/or instrumental piece based on their chosen traditional song in order to give a personal view of the tradition as seen from the present day.

\section{The images}

Once the musical composition was completed, the students began producing the video with the help of teachers from the artistic and visual arts area. They were guided by the following structure: during the introduction and the reciting of the quartets the visual sequences reflect moments from the process, such as photographs or videos of students playing instruments, singing, exchanging opinions, etc. In the tercets, the images selected represent some of the aspects related to the topic and/or the region. The order of this structure would vary depending on the aesthetic choices made by each group.

\section{Editing and production phase}

One of the key threads in the process was to understand technology as a resource for enriching the musical experience (Webster 2002). Production tasks involved in audiovisual editing were carried out at this point in the process. From the perspective of digital competency and the use of technology, teachers from the area of technology kept in mind the diversity and heterogeneity of the groups' knowledge and use of tools so as to ensure that they would all work to achieve the same objectives. The video ended with 
the credits and, in some cases, incorporated a making of in which the students commented on their satisfaction and motivation, as substantiated in the evaluation section.

\section{Presentation phase}

All groups presented their productions in each of the universities in person and virtually on the shared platform (wiki). This allowed the students from the four universities to see the other groups' work and give their opinions about it. Technology provides teachers and students with the means to research, monitor and supervise, which encourages participation, musical development and emotional commitment through music and sound (Himonides and Purves 2010).

In addition, a public recital was given in two of the universities, the Balearic Islands and Cantabria, attended by the university community, family and friends. The students of these universities presented the different phases of the creative process: they recited the sonnets, performed the musical compositions and showed the videos, sharing and transmitting the results of their work. Performing in public has been shown to increase motivation to continue with the practice, and, if successful, has a positive impact on self-esteem and confidence (Papageorgi and Hallam 2010). This positive experience encourages participants to develop projects using new methodological approaches in their future careers as teachers.

\section{Virtual space: Feedback space}

The wiki tool enabled the teachers to engage with students through stimulating feedback, following the idea that successful student learning depends on appropriate feedback (Papageorgi and Hallam 2010). 
The virtual platform was divided into different sections to make it easier for teachers and students to use. The project was presented in the first tab, home, and established common guidelines that the students from the four universities should follow. In the second tab, materials, teachers from various disciplines (music, literature, visual arts and technological resources) provided and shared work and support materials for the project. The next ten tabs covered each of the ten intangible heritage topics for the four Spanish regions.

The students from each university used this virtual space to correspond on the development of the creative process in the stages described above (documentary and analysis phases, creative phase - the sonnet, the music, the images - editing and production phase and presentation phase). The students and teachers involved were therefore able to follow the progress of each sonnet and make comments and contributions if they so wished.

The virtual space also acted as a source of inspiration for students carrying out their own work and as a meeting point where the groups could harmonize their final productions. The localization and globalization of education has created an environment in which distance and time are no longer obstacles to information exchange, and where the local and global can interweave (Kruse et al. 2013).

Once the work was completed the videos from the four universities were uploaded onto the virtual platform. A montage of ten videos, one for each core topic, articulated and reflected the final result of the travelling sonnet.

\section{Data collection and evaluation}


Zubimendi et al. (2010) identify two basic aspects in evaluating cooperative learning: the process the students followed, and the content or outcomes (written documents, reports, assignments, oral presentations, etc.).

Following these authors, we chose a continuous and educational form of assessment that would analyse and evaluate observable behaviours, skills and knowledge such as processes of thought, analysis and interpretation, complex research skills, understanding and problem solving and that would be presented both as information and guidance. During the sessions various interventions were proposed to collect information on the project. The following tools were used in the data gathering process:

\section{Students}

We designed a survey consisting of eight open questions agreed upon by the teachers from the universities involved to be completed by each group of students at the end of the project on issues related to the internal workings of the group, distribution of tasks, group cohesion, difficulties during the process, solutions provided, roles, capacity for synthesis, creativity, constructive thinking, etc.

The group questionnaire included the following eight enquiries to evaluate the experience:

1. What were the group meetings like? How much time did you spend in the meetings and what were the main questions dealt with there?

2. How was the work shared among the group members?

3. What difficulties arose and how did you solve them?

4. What did you get out of a project of this nature? 
5. What aspects of the overall creative process of this experience would you highlight?

6. What did you aim to achieve in your audio-visual artistic production?

7. What use(s) do you think this activity has for primary education?

8. In what way(s) do you think this experience could be improved?

A second questionnaire was also designed to gather information and to allow the students to express their individual opinions on specific areas of the project.

The questionnaire asked about the following seven aspects:

1. Acquisition of basic and transversal competencies

2. Creativity

3. Interdisciplinary work

4. Group work

5. Knowledge of the cultural and musical heritage from different Spanish regions

6. Use of ITC tools in new teaching-learning methodologies in developing and coordinating the project

7. Use of ITC as an inter-university communication tool

This evaluation process also took into account students' self-critical evaluation, the groups' assessments and the teachers' assessments. Organizational elements and coordination were assessed, together with the material included in the portfolio (texts, photographs, sheet music), the sound and audio-visual recordings and the final result of the presentation. 


\section{Teachers}

The teachers were also asked to note their individual assessments of the project's strengths and weaknesses. The results were then pooled and analysed to discover the extent to which they coincided with the students' assessments.

\section{Results}

\section{Work groups}

From the analysis of the open responses to the group survey we classified the results into two columns, strengths and weaknesses, which report the phrases the groups most frequently mentioned. ${ }^{1}$

[Insert Table 1 here]

\section{Individual student survey}

The following table contains some of the students' comments, corroborating the results reported above that we considered to be the most relevant.

[Insert Table 2 here]

\section{Teachers}

As with the groups, the teachers' viewpoints, self-assessments and evaluation are reported as strengths and weaknesses in the following table. 


\section{[Insert Table 3 here]}

\section{Discussion}

This experience has shown how technology and an interdisciplinary approach to musical activities can motivate the enjoyable and creative exploration of knowledge about traditional culture and provide an excellent resource to encourage the transfer of cultural heritage. Similarly, as Johnson and Johnson (1997) state, we were able to observe how the work in the classroom through cooperative learning encourages critical thinking, an increased number and quality of ideas, feelings of stimulation, and originality of expression in creative problem solving.

Students from different universities could share the culture and music of each regional tradition on the virtual platform. Teacher-training students can use their first-hand experience of this project to extend it to children in school. With today's technologies cultural exchange can be established between school classes in different parts of the country or different countries, once again improving intercultural understanding through personal commitment (Lum and Marsh 2012).

The guidelines provided for students to self-assess the project made them aware of the importance of facing new challenges that may initially appear complex, through collaborative work that brings together different capabilities with a common purpose and respects different paces of learning. Technology was incorporated as another tool to serve the broad areas of research, learning and creativity.

The results of the student surveys show that experiences like this one give students the opportunity to actively participate in learning, and to work with music in an interdisciplinary way, as well as encouraging creativity. Given that ICT is now an important part of children's lives outside the classroom, it is vital that all children have 
the opportunity to acquire skills in music technology. To make this possible a number of changes are crucial in initial teacher training and ICT must become an essential part of the subject of music taught in undergraduate studies (Gall 2013). According to Ellison and Creech, 'provision of adequate training and support for classroom teachers and subject leaders in music is challenging' (2010: 219).

Most of the groups agreed that the group work had been organized in an equitable way and tasks distributed fairly, with each group member's knowledge being taken into account. The way the teachers structured the project also encouraged everyone to participate. The survey also highlighted the creative role; students discovered aspects about themselves that they had not had the opportunity to develop until they took part in this interdisciplinary experience.

We have shown that students - future teachers - are capable of performing creative, original, structured activities of high technical quality in an autonomous way, and of taking creative decisions based on their own learning experience, which also reflects the huge potential of new technologies as teaching tools. According to Himonides (2012), technology allows us to challenge the world, question certainties, increase knowledge, shape attitudes and communicate more quickly. Moreover, technology is not something we can choose to ignore: it is now an integral part of our human condition.

\section{Conclusions}

Having evaluated the strategies and techniques used in the activities and the students' and teachers' critical self-assessment, we can highlight that the experience enhanced the acquisition of basic and transversal competencies, creativity and group work. It improved knowledge about the cultural heritage in other Spanish regions through 
traditional songs, customs, dances and other aspects of each of the regions. It also enabled the use of ICT tools in new teaching-learning methodologies, in the development and coordination of the students' and teachers' work and as a tool for inter-university communication. We can therefore state that the aims proposed in the design of the experience were satisfactorily fulfilled.

The students observed that the experience showed them a useful resource for their future teaching careers as it helped them understand how to integrate different competencies in a common project, which also fosters collaborative work, and that can be especially enjoyable and motivating to transmit and share cultural, and therefore musical, heritage. From the teachers' perspective, the experience was regarded as an efficient, enriching proposal that facilitated certain learning processes.

\section{Limitations of the study and future perspectives}

Another particularly rewarding aspect that emerged from the analysis of the results was the requirement to apply competencies (technological, linguistic, musical, etc.) and pool diverse skills. Although the experience was largely evaluated as very positive by both students and teachers, it also revealed aspects that need to be revised. Perhaps what most drew our attention was the students' limited use of the virtual platform to exchange opinions. Given the widespread use of these media by young people in their leisure time, this suggests that they believe, in the main, that discussion of academic questions still belongs in the classroom. A more fluent dialogue of exchange among the students at the different universities would have made the experience more enriching for all the participants. 
The methodological proposal can be used not only in the specific area in which it was developed, namely university teacher-training degrees, but we believe that it can also be used with secondary school students. According to Cain (2013), it is important for secondary school students to acquire knowledge and skills through different proposals that allow them to become competent users of digital technologies.

Finally, the travelling sonnet experience is being applied in four institutions in Argentina following the proposal design described in this article. These institutions are the National University of San Juan, the Provincial Conservatoire of Music 'Reverendo Padre Eugenio Rosso' in Ciudad de Río Gallegos, the Higher School of Artistic Education Teachers 'Nicolás Segundo Gennero' in Santiago del Estero, and the Higher Institute of Art 'Oscar Alberto Albertazzi' in the province of Formosa. The initial results are similar to those from the Spanish experience. We are also in contact with other institutions in European countries that have expressed an interest in replicating the travelling sonnet experience in their classrooms.

\section{Acknowledgements}

The authors acknowledge funding from the Ministry of Economy and Competitiveness for the Project 'Música, danza y ritual en el encuentro iberoamericano. El patrimonio compartido y su trascendencia en la educación' (Music, dance and ritual in the IberoAmerican encounter. The shared heritage and its importance in education), HAR201130164-C03-03. The present study was carried out as a part of this project.

\section{References}


Cain, T. (2013). Investigación-acción en educación musical/‘Action-research in music education'., in M. Díaz and A. Giráldez (eds), Investigación cualitativa en educación musical/ 'Qualitative research in music education', Barcelona: Graò, pp. $57-75$

Ellison, J. and Creech, A. (2010), 'Music in the primary school', in S. Hallam and A. Creech (eds), Music Education in the 21st Century in the United Kingdom. Achievements, Analysis and Aspirations, London: Institute of Education, University of London, pp. 211-227.

Escamilla González, A. (2008), Las competencias básicas. Claves y propuestas para su desarrollo/'The basic competences. Keys and proposals for their development', Barcelona: Graó.

(2009), Las competencias en la programación de aula/ 'The competences in classroom programming', Barcelona: Graó.

Froehlich, H. C. (2007), Sociology for Music Teachers: Perspectives for Practice, New Jersey: Pearson.

Gall, M. (2013), 'Trainee teacher's perceptions: Factors that constrain the use of music technology in teaching placements', Journal of Music, Technology \& Education, 6:1, pp. 5-27. 
Giráldez Hayes, A. (2013), 'Enseñar artes en un mundo digital: Diez propuestas para la formación del profesorado’/‘Teaching the arts in a digital world. Ten proposals for teacher training', PÓS: Revista do Programa de Pós-graduação em Artes da Escola de Belas Artes da UFMG, 3:5, pp. 85-104.

Himonides, E. (2012), 'The misunderstanding of music-technology-education: A meta perspective', in G. E. McPherson and G. Welch (eds), The Oxford Handbook of Music Education, New York: Oxford University Press, pp. 433-56.

Himonides, E. and Purves, R. (2010), 'The role of technology', in S. Hallam and A. Creech (eds), Music Education in the 21st Century in the United Kingdom. Achievements, Analysis and Aspirations, London: Institute of Education, University of London, pp. 123-40.

Johnson, R.T. and Johnson, D.W. (1997), 'Una visiò global de 1'aprenentge cooperatiu' /‘An Overview of Cooperative Learnin', Suports: Revista catalana d'educació especial $i$ atenció a la diversitat, 1: 1, pp. 54-64.

Johnson, D. W., Johnson, R. T. and Holubec, E. J. (1994), Cooperative Learning in the Classroom, Virginia: Association for Supervision and Curriculum Development. 
Kruse, N. B., Harlos, S. C., Callaham, R. M. and Herring, M. L. (2013), ‘Skype music lessons in the academy: Intersections of music education, applied music and technology', Journal of Music, Technology \& Education, 6:1, pp. 43-60.

Lum, C. and Marsh, K. (2012), 'Multiple worlds of childhood: Culture and the classroom', in G. E. McPherson and G. Welch (eds), The Oxford Handbook of Music Education, New York: Oxford University Press, pp. 381-398.

Malbrán, S. (2010), 'El pensamiento metafórico en las artes'/‘The metaphoric thinking in the arts', in S. Espinosa (ed.), Artes integradas y educación. Colección Humanidades y Artes/'Integrated arts and education. Collection Hummanities and Arts', Buenos Aires: Universidad de Lanús, pp. 34-42.

Ministry of Education of Spain (2007), 'Ministerial Order ECI/3857. 22449', Official Bulletin of the State, Nr. 312, 29 December, pp. 53747-50.

Papageorgi, I. and Hallam, S. (2010), 'Issues of assessment and performance', in S. Hallam and A. Creech (eds), Music Education in the 21st Century in the United Kingdom. Achievements, Analysis and Aspirations, London: Institute of Education, University of London, pp. 141-58.

Roegiers, X. (2007), Pedagogía de la integracción. Competencias e integración de los conocimientos en la enseñanza/'Pedagogy of the integration. Competences and 
integration of the knowledge in teaching', San José, Costa Rica: Coordinación Educativa y Cultural Centroamericana y AECI.

UNESCO (1998), 'World declaration on higher education for the twenty-first century: Vision and action', World Conference on Higher Education, Paris, France, 9 October, http://www.unesco.org/education/educprog/wche/declaration_eng.htm. Accessed 6 February 2015.

(2003), 'Convention for the safeguarding of the intangible cultural heritage', 32th General Conference of the United Nations Educational, Scientific and Cultural Organization, Paris, France, 29 September-17 October.

Webster, P. (2002), 'Computer-based technology and music teaching and learning', in R. Colwell and C. Richardson (eds), The New Handbook of Research on Music Teaching and Learning, New York: Oxford University Press, pp. 1311-28.

Zubimendi, J. L., Ruiz, M. P., Carrascal, E. and De La Presa, E. (2010), El aprendizaje cooperativo en el aula universitaria: Manual de ayuda al profesorado/'Cooperative learning in the university classroom: Handbook of support for teachers', Bilbao: Universidad del País Vasco.

\section{Contributor details}


Noemy Berbel Gómez is currently lecturing at the University of the Balearic Islands, Spain. She obtained a Ph.D. in Educational Research and Innovation from this University. She has a Degree in Music, in the specialities of Piano, Music Theory, Transposition and Accompaniment, Music Pedagogy, and Harmony, Counterpoint and Composition at the Conservatorio Superior de Música of the Balearic Islands. She has also a Degree in Economics from the University of the Balearic Islands. Her research interests focus on music education, creativity and interdisciplinarity and evaluation of educational centres. She has presented several works at national and international conferences, and has published articles in books and specialized journals.

Alberto Cabedo Mas is Senior Lecturer at the University Jaume I of Castellón, Spain. He studied music, with a speciality in violin, at the Conservatorio Superior de Música in Castellón and got a Master's degree in Music at the Estonian Academy of Music and Theatre, in Tallinn, Estonia, and a Master's degree in Peace Studies, Conflict and Development at the University Jaume I of Castellón, Spain. He obtained his Ph.D. at this University. He is author of several publications in books and specialized journals. His research interests include music education, musical heritage, coexistence, interculturality and the transmission of music across cultures.

María Elena Riaño Galán (Ph.D.), formally trained as a pianist, is currently lecturing Music Education at the University of Cantabria, Spain, in the Bachelor Degree for Primary School Teachers and in the Master of Research and Innovation in Educational Contexts. She has also been in charge of the Musical Management in this university (2009-2012) as well as being President of the Society for the Musical Education of the Spanish State, SEM-EE (2006-2011), affiliated to ISME. Her interests are related to 
Creativity, Musical Education in early childhood and Interdisciplinary Projects. She has published articles in specialized journals, edited some books and collaborated in writing some chapters in others. She is presently working on a nationwide project researching on musical heritage.

Cristina Arriaga Sanz is teacher of Music Pedagogy and has got a Ph.D. in Philosophy and Educational Sciences. She is currently Full Professor in the area of Didactics of the Musical Expression at the University of the Basque Country, Spain. She is author of several publications on motivation in music learning in primary education, mainly in its relation with teachers' performance and the interactions that occur during music education practices. She has also researched on traditional music and its didactic approach, and on the use of multimedia resources in the artistic education for preservice teachers.

Maravillas Díaz Gómez is Full Professor at the University of the Basque Country, Spain. She has got a Ph.D. in Philosophy and Educational Sciences. Her research interests include contemporary music, curriculum, creativity and interculturality. She is author of several publications in books and specialized journals. She has participated in numerous national and international scientific committees as expert evaluator. She is co-director of the journal Eufonía: Didáctica de la Música and assignment editor of the Journal of Psychodidactics. She is the director of the Master's Degree of Research in Psychodidactics: Educational Psychology and Specific Didactics, at the University of the Basque Country.

Contact: 
Noemy Berbel-Gómez, University of the Balearic Islands, Cra. de Valldemossa, Km. 7.5, Guillem Cifre de Colonya Building, Palma de Mallorca (Balearic Islands), 07122, Spain. Email: noemy.berbel@uib.es

Alberto Cabedo-Mas, Facultat de Ciències Humanes i Socials, University Jaume I of Castellon, Av. Vicent Sos Baynat, s/n, 12071, Castellon de la Plana, Spain. Email: cabedoa@uji.es

María-Elena Riaño-Galán, Universidad de Cantabria, Edificio Interfacultativo, Avda Los Castros, s/n, 39005, Santander (Cantabria), Spain. Email: elena.riano@unican.es

Cristina Arriaga Sanz, Department of Didactics of Musical, Plastic and Corporal Expression, University of the Basque Country, Barrio de Sarriena, s/n, Leioa, 48940, Spain. Email: cristina.arriaga@ehu.es

Maravillas Díaz-Gómez, Department of Didactics of Musical, Plastic and Corporal Expression, University of the Basque Country, Barrio de Sarriena, s/n, Leioa, 48940, Spain. Email: maravillas.diaz@ehu.es

Note

\footnotetext{
${ }^{1}$ For the sake of simplicity, the following abbreviations are used: University of the Basque Country (UPV), University of Cantabria (UC), University Jaume I (UJI), University of the Balearic Islands (UIB).
} 